\title{
Author's Response to Peer Reviews of "Risk Factors of SARS-CoV-2 Infection: Global Epidemiological Study"
}

William Alphonse Barletta, PhD

Department of Physics, Massachusetts Institute of Technology, Cambridge, MA, United States

Corresponding Author:

William Alphonse Barletta, $\mathrm{PhD}$

Department of Physics

Massachusetts Institute of Technology

77 Massachusetts Avenue

Cambridge, MA, 02142

United States

Phone: 15102820240

Email: barletta@mit.edu

\section{Related Articles:}

Preprint (medRxiv): https://www.medrxiv.org/content/10.1101/2020.09.30.20204990v1

Preprint: https://preprints.jmir.org/preprint/28843

Peer-Review Report by Anonymous: https://med.jmirx.org/2021/3/e31926/

Peer-Review Report by Palash Banik (Reviewer D): https://med.jmirx.org/2021/3/e31927/

Published Article: https://med.jmirx.org/2021/3/e28843/

(JMIRx Med 2021;2(3):e31910) doi: 10.2196/31910

\section{KEYWORDS}

COVID-19; pandemic; public health; mortality; infection; risk; risk factors; age; epidemiology; infectious disease

This is the author's response to peer-review reports submitted for the paper "Risk Factors of SARS-CoV-2 Infection: Global Epidemiological Study".

\section{Round 1 Review}

Author's response to the review of the manuscript:

1. The Abstract and body of the text of the manuscript [1] have been restructured to conform with the standard format of the journal (ie, Background, Objective, Method, Results, Conclusions).

2. The revised text is based on the updated manuscript as recommended by the editor.
3. Figures that were suggested for deletion have been removed. All figures have been sized and reformatted per journal policy.

4. All footnotes have been removed, and the relevant information has been made part of the text or a numbered reference.

5. Equations are numbered for appropriate reference in the text.

6. I have added some quantitative values in the Results section of the Abstract.

7. I have removed the author-defined acronym, "CFR," for apparent case fatality ratio.

8. Two references have been added in the Summary section.

9. The Summary and Conclusions have been expended to suggest potential effects of new SARS-CoV-2 variants.

\section{Conflicts of Interest}

None declared.

\section{Reference}

1. Barletta WA. Risk factors of SARS-CoV-2 infection: global epidemiological study. JMIRx Med 2021 Aug 18;2(3):e28843 [FREE Full text] [doi: 10.2196/28843] 
Edited by E Meinert; this is a non-peer-reviewed article. Submitted 08.07.21; accepted 08.07.21; published 26.08.21.

Please cite as:

Barletta WA

Author's Response to Peer Reviews of "Risk Factors of SARS-CoV-2 Infection: Global Epidemiological Study"

JMIRx Med 2021;2(3):e31910

URL: https://med.jmirx.org/2021/3/e31910

doi: $\underline{10.2196 / 31910}$

PMID:

(C) William Alphonse Barletta. Originally published in JMIRx Med (https://med.jmirx.org), 26.08.2021. This is an open-access article distributed under the terms of the Creative Commons Attribution License (https://creativecommons.org/licenses/by/4.0/), which permits unrestricted use, distribution, and reproduction in any medium, provided the original work, first published in JMIRx Med, is properly cited. The complete bibliographic information, a link to the original publication on https://med.jmirx.org/, as well as this copyright and license information must be included. 